\title{
Learning to in Complement Constructions ${ }^{1}$
}

\author{
Lois Bloom, Jo Tackeff, and Margaret Lahey
}

Citation: Bloom, L., Tackeff, J., and Lahey, M. (1984). Learning to in Complement Constructions, Journal of Child Language, 11, 391-406. Reprinted in Bloom, L. (1991). Language development from two to three, New York: Cambridge University, pp. 292-309.

\begin{abstract}
The acquisition of to in infinitive complement structure was examined in the spontaneous speech data from four children who were observed longitudinally from two to three years of age. The children learned to as a complementizer connective in the context of a small group of verbs and other matrix forms that take a verb phrase complement. They did not learn to in the context of the complement verbs to mark the infinitive. Secondly, the children learned to with the meaning 'direction towards' and not as a meaningless syntactic marker. These results contribute to understanding the relation between the acquisition of complex syntax and the verb system in child language, and to evaluating traditional and contemporary linguistic theories of infinitive complement structure in English.
\end{abstract}

The transition from simple to complex syntax ordinarily begins between 2 and 3 years of age, and the structure of infinitive complements is one of the first complex structures to appear (Brown, 1973; Limber, 1973). Certain other linguistic structures that children begin to acquire in this period have been highly constrained by the kinds of verbs that they know and use, in particular, the acquisition of verb inflections (Bloom, Lifter, \& Hafitz, 1980) and $w$ h-questions (Bloom, Merkin, \& Wootten, 1982). Because sentences with infinitive complements include two verbs, how children acquire infinitive complements is relevant to extending our understanding of the relationship between the acquisition of complex syntax and the development of the verb system in child language. One purpose of this study, then, was to determine whether regularities among the higher verb forms (hereafter referred to as matrix forms) or the complement infinitive verbs governed acquisition of to as a syntactic marker.

In addition, among the reasons for studying child language is the continuing concern for understanding the nature of language more generally. How children acquire language is relevant to how we attempt to explain language. The study of one or another aspect of language development, then, can be helpful in evaluating alternative theories of language. In the case of the acquisition of infinitive complements, we have several theories but no consensus about their structure in adult language. A second purpose of this study, then, was to evaluate the extent to which child data are consistent with traditional and contemporary theories of infinitive complement structure.

In many linguistic accounts, the connective to is presented as part of the larger system of complementation in English and, in particular, to complements are contrasted with participial -ing complements (e.g., Quirk, Greenbaum, Leech, \& Svartvik, 1972; Rosenbaum, 1967). However, to complementation was the subject of the separate study reported here because (1) the children in this longitudinal study did not acquire participial -ing complements in the same period (from 2 to 3 years of age), so that to complements were not learned contrastively,

${ }^{1}$ The research reported here was supported by Fellowship F1-MH-30,001, 1965-1968, from the National Institute of Mental Health; Research Grant HD 03828, 1971-1974, from the National Institute of Child Health and Development; and Research Grants from the National Science Foundation, 1975-1987, to Lois Bloom. The study was published originally in the Journal of Child Language, 11, 1984, 397-406; reprinted in Bloom, L. (1991). Language development from two to three, New York: Cambridge University, pp. 292-309; and reformatted for this digital version with slight changes in organization and minor text editing. 
and (2) to complements have recently been singled out in theories of adult complementation for different theoretical reasons.

For example, in explanations of the occurrence of to in infinitive complements in such sentences as:

(1 a) I want to go home.

(1 b) He likes to sleep.

to is considered a meaningless, purely syntactic device. Historically, verbal to was derived from the preposition to with nouns and originally retained the prepositional meaning of direction toward, purpose, or goal (Jespersen, 1964). Even though "a trace of this meaning" remains in certain instances (as in the examples "ready to go, I wish to go,") the meaning has been "gradually obliterated," and Jespersen described contemporary to in verb contexts as "a grammatical implement with no meaning of its own" (1964, p. 330). Similarly, transformational accounts also describe complementizer connectives as semantically empty (Bresnan, 1970, p. 302). However, Bresnan pointed out that differences in sentence meaning result from the choice of different connectives (e.g., sentences with for-to versus that), so that they do serve semantic as well as syntactic functions. In the present study, children's spontaneous speech was examined to determine whether to was learned as a meaningless syntactic marker or with particular meaning, such as the prepositional meaning "direction toward" with nouns.

With respect to the syntactic function of to in complement structures, Jespersen suggested that "to is often felt as belonging more closely to the preceding verb than to the infinitive" (1964, p. 346). Virtually all accounts of English grammar subcategorize verb entries in the lexicon for taking to complements. However, two contemporary theories differ with respect to the underlying syntax of infinitive complements in the adult model (Koster \& May, 1982; Bresnan, 1978). The transformational account by Koster and May is consistent with standard generative theory in treating all infinitive complements as sentential and derived from the same underlying sentence structure as for complementizers. They proposed that sentences like

(2) John tried to leave.

are derived from the same constituent structure as sentences like

(3) Mary prefers for John to leave.

with the "superficially absent complementizer and subject," for example, for and the subject of the verb leave in (2), John tried [for John] to leave, "being represented by lexically empty categories" (Koster \& May, 1982, p. 116). The child speech data in the present study were examined to determine if to was learned originally in sentential contexts with for complementizers and sentence subjects, such as (3).

In contrast, Bresnan proposed that the "verb + infinitive construction is a basic structure, like the modal + infinitive construction." Both are generated "by means of a phrase structure rule VP $\rightarrow$ V VP," where the lower verb in the second VP is the infinitive with to (Bresnan, 1978, pp. 44-45). The infinitive complement with to is itself the basic, underlying structure and is not derived from a more complex underlying sentence structure. In the study reported here, the spontaneous child speech data were used to determine whether to was learned originally as a marker of the infinitive or as a complement connective with the higher verb or other matrix forms.

\section{SUBJECTS AND PROCEDURES}

Transcripts of the naturally occurring speech of four children, annotated with descriptions of context and relevant activity, were examined for evidence of (1) the developing productivity of complement-taking verbs; (2) their discourse contexts; and (3) the surface structures of sentences with matrix verbs, including complement type and complementizer connectives.

\section{The Children}

The four children-Eric, Gia, Kathryn, and Peter-were born in the 1960s, the first-born children of white, collegeeducated parents who lived in university communities in New York City. Their parents were native speakers of American English and their mothers were their primary caregivers. They were chosen as subjects with these qualifications in what turned out to be, in retrospect, a naive effort to come up with a 'homogeneous' population. 
Since parent education, birth order, and economic differences among children had been found to be sources of individual differences in speech and language in other studies, these were the minimal 'controls' that seemed feasible to ensure that the children would be similar in their language learning. ${ }^{2}$

Eric, Gia, and Kathryn were each visited in their homes for approximately eight hours over several days, every six weeks; Peter was visited for approximately six hours every three weeks. The visits occurred in the context of their daily activities and informal play with a familiar adult (the investigators) and, less often, with their mothers. The same or similar toys were brought to all the sessions, for the different children and for each child, in an effort to establish consistency in the home contexts among the children and over time. The observations were audio recorded, and the transcriptions included all speech by child and adult, along with descriptions of nonlinguistic context and behavior. 3

\section{Procedures}

Because we cannot tap their intuitions about language by asking them directly to tell us what is possible or acceptable to them linguistically, we need to infer what children know about language from the evidence of the regularities in their language behaviors. Accordingly, a systematic distribution among large numbers of linguistic events is taken as evidence for inferring a principled organization underlying a child's language behavior. A sizable and coherent shift in the regularity of behavior across time, from one observation to a later observation, is taken as evidence of developmental change. In order to establish confidence that the regularities in the children's speech behaviors represented evidence of linguistic knowledge, a criterion of productivity was established in advance. The criterion of four different instances of a linguistic behavior (such as occurrence of to) in one text, from one child, was assumed to be minimal evidence for inferring some level of underlying knowledge, at that time, for that child.

The texts that were used began when at least four linguistic contexts for to with infinitive complement verbs (hereafter identified as CV contexts) were observed. This occurred at between 22 and 25 months for each of the children, and data analysis continued until the last observation of each child at about 36 months. Data from six observation sessions are reported for Eric and Kathryn; five observations are reported for Gia; and for Peter, who was seen for shorter sessions with shorter intervals between sessions, data are reported for eight observation sessions.

For this study, two complement verb (CV) contexts for to were identified. The first CV context was the V-to-V context, as in

\section{(4) I want to see Mommy.}

with no intervening noun phrase and with coreferential subject of both verbs, want and see in (4). The second $\mathrm{CV}$ context was V-NP-to-V, as in

\section{(5) I want Mommy get balloon.}

where an intervening noun phrase was the subject of the second, complement verb phrase and was not coreferential with the subject of the matrix verb. These CV contexts were extracted from the texts for analysis, whether or not to or some phonological variant of to (such as [ə], schwa) was expressed. The matrix forms with these CV contexts for to included forms that were verbs, such as want, try, and like, as well as other forms that

\footnotetext{
2 However, see Bloom (1992) for a later appraisal of this decision.

3 The procedures for data collection and transcription are described in greater detail in Bloom (1970, pp. 234-9). See, also, Bloom, Lightbown, and Hood (1975) and conventions for transcription of child language recordings, App. A, in Bloom \& Lahey (1978). The speech samples from Eric, Gia, and Kathryn were collected and transcribed by Lois Bloom. The speech samples from Peter were collected and transcribed by Lois Hood and Patsy Lightbown, who took turns interacting with Peter and taking notes on the situational context and behavior. The transcriptions of the Eric, Gia, Kathryn, and Peter data are stored for access by other researchers in the Special Collections at the Gottesman Memorial Libraries, Teachers College, Columbia University; transcripts of the Peter data are also part of the CHILDES database, the Child Language Data Exchange System, Carnegie-Mellon University.
} 
acted like verbs, such as ready and about. The estimated total number of utterances in the texts from the four children was 78,986, and 3,798, or .048, of these utterances included a CV context for to.

Subsequently, in order to compare emergence and use of to in CV contexts with to in noun (N) contexts as a preposition, all the children's utterances with a V-to-N context, as in

I'm going to school.

were extracted from the early texts. The texts before as well as after to emerged in CV contexts were examined.

All the analyses were performed separately for each observation of each of the children. When a result was the same for the four children, the data were pooled for convenience of presentation. The first step in combining the data from the four children was to consider the last four observations of each of the children (until they were about 36 months old) as four longitudinal periods. These were labeled Periods A, B, C, and D. For example, Period D included the four texts from the four children at about 36 months of age; Period C included the four texts from the immediately preceding observations; and so on. The second step was to include two exceptions: Period A also included the immediately preceding texts from two of the children, Kathryn and Peter, who began to acquire new matrix forms earlier than the others, and Period D also included the later text from Peter who was followed for a longer period of time than the others (until 38 months of age).

\section{The Status of [ə] in Verb Contexts}

While wanna, gonna, hafta are acceptable variants of to with want, go, and have in adult American English, the status of the final [ə] in the child forms was initially ambiguous. In contexts with want, the function of [ə] was either as a variant of to as in (7), a variant of the article $a$ as in (8), or wanna was an unanalysed lexical item as in (9).

(7) wanna go playground.

(8) Gia wanna train.

(9) wanna more cookie.

In the early texts, [ə] occurred after want before both noun phrases and verb phrases. For example, in the earliest Gia text that included want, [ə] (wanna) occurred with a noun or pronoun in 8 out of 50 instances of want. Thus it was difficult to support an unequivocal interpretation of [ə]. Further, want, go, and have occurred primarily with first-person subjects as the apparently unanalyzed forms wanna, gonna, and hafta. It was only in the later observations, when [ə] began to occur in third-person contexts, for example:

(10a) he has [ə] go home.

(10b) she wants [ə] get it.

that it appeared more reasonable to consider [ə] to be a variant of to. However, because of the difficulty in supporting an unequivocal interpretation of [ə] in the earlier texts, the use of [ə] and to are reported separately in the analyses of CV contexts that follow.

\section{RESULTS}

The results of the analyses of the children's utterances with linguistic contexts for the use of to consist of (1) the developmental distribution of to with different matrix forms in CV contexts; (2) the comparison of the distributional regularities of to with old and new matrix forms and complement verbs; (3) the occurrence of to in CV contexts with an intervening noun phrase; (4) acquisition of for-to complement structures; (5) semantic consistencies among the matrix forms in CV contexts for to; and (6) the comparison of the emergence of to in CV and $\mathrm{N}$ contexts. 
Acquisition of to with Different Matrix Forms

Both contexts for to and occurrences of to in those contexts increased developmentally, as can be seen in Table 1. For all four children, to emerged in CV contexts (in that to first became productive, with four different instances) when MLU was about 2.5. After MLU passed 3.5, the children were using to or [ə] in at least $75 \%$ of CV contexts for to.

Table 1. Distribution of to and the Different Contexts for to

\begin{tabular}{|c|c|c|c|c|c|c|c|c|c|c|}
\hline \multirow[b]{2}{*}{$\begin{array}{l}\text { Child } \\
\text { and } \\
\text { Period }^{\mathrm{b}}\end{array}$} & \multirow[b]{2}{*}{$\begin{array}{l}\text { Observ- } \\
\text { ation }\end{array}$} & \multirow[b]{2}{*}{ Age } & \multicolumn{4}{|c|}{ Verb-to-Verb } & \multicolumn{2}{|c|}{ Verb-NP-to-Verb } & \multicolumn{2}{|c|}{ Verb-to-Noun ${ }^{\mathrm{a}}$} \\
\hline & & & MLU & $\begin{array}{r}\text { Total CV } \\
\text { Contexts } \\
\text { for to }\end{array}$ & + to & [ə] & $\begin{array}{r}\text { Total CV } \\
\text { Contexts } \\
\text { for to }\end{array}$ & + to & $\begin{array}{r}\text { Total } \mathrm{N} \\
\text { Contexts } \\
\text { for to }\end{array}$ & + to \\
\hline \multicolumn{11}{|l|}{ Kathryn } \\
\hline & II & 22,3 & 1.89 & 32 & $1(.03)^{\mathrm{c}}$ & $2(.06)$ & 6 & - & - & - \\
\hline A & III & 24,2 & 2.83 & 222 & ${ }^{*} 5(.02)^{\mathrm{d}}$ & $64(.29)$ & 20 & - & 7 & $1(.14)$ \\
\hline A & IV & 26,1 & $3 \cdot 30$ & 328 & $121(.37)$ & $35(.11)$ & 11 & - & 14 & *6 (.43) \\
\hline B & VI & 29,1 & 3.35 & 171 & $57(.33)$ & $90(.53)$ & 3 & $2(.66)$ & 38 & $36(.95)$ \\
\hline $\mathrm{C}$ & VIII & 32,1 & $3 \cdot 70$ & 211 & $150(.71)$ & 41 (.09) & 4 & $3(.75)$ & - & \\
\hline $\mathrm{D}$ & $\mathrm{X}$ & 35,1 & 4.23 & 306 & $159(.52)$ & $128(.42)$ & 27 & $*_{27}(1.0)$ & - & \\
\hline \multicolumn{11}{|l|}{ Eric } \\
\hline & IV & 23,2 & 1.69 & - & - & - & - & - & 4 & $1(.25)$ \\
\hline & $\mathrm{V}$ & 25,1 & 2.63 & 47 & ${ }^{*} 16(.24)$ & $20(.30)$ & 3 & - & 6 & $*_{4}(.25)$ \\
\hline A & VI & 26,3 & 2.84 & 67 & $16(.24)$ & $20(.30)$ & 3 & - & 4 & $3(.75)$ \\
\hline B & VIII & 29,3 & 3.45 & 73 & $56(.77)$ & $9(.12)$ & 4 & $1(.25)$ & 22 & $22(1.0)$ \\
\hline $\mathrm{C}$ & $\mathrm{X}$ & 33,0 & 4.21 & 57 & $41(.72)$ & $8(.14)$ & 8 & *8 (1.0) & - & \\
\hline $\mathrm{D}$ & XII & 36,0 & 3.49 & 63 & $45(.71)$ & $10(.16)$ & 11 & $11(1.0)$ & - & \\
\hline \multicolumn{11}{|l|}{ Gia } \\
\hline & $\mathrm{V}$ & 25,2 & 2.30 & 158 & 2 (.01) & $42(.26)$ & - & - & 16 & $2(.13)$ \\
\hline A & VI & 26,3 & 2.75 & 129 & $*_{21}(.16)$ & $51(.39)$ & - & - & 24 & ${ }^{*} 7$ (.29) \\
\hline B & VII & 28,1 & 3.07 & 243 & $29(.12)$ & $60(.25)$ & 4 & $1(.25)$ & 9 & $6(.66)$ \\
\hline $\mathrm{C}$ & VIII & 29,3 & 3.64 & 358 & $46(.13)$ & $198(.55)$ & 2 & - & 24 & $23(.96)$ \\
\hline $\mathrm{D}$ & XI & 34,2 & 3.71 & 268 & $103(.38)$ & $145(.54)$ & 31 & $*_{29}(.94)$ & 76 & 75 (.99) \\
\hline \multicolumn{11}{|l|}{ Peter } \\
\hline & VII & 25,0 & 2.39 & 19 & - & $16(.84)$ & - & - & - & - \\
\hline & VIII & 25,3 & 2.0 & 11 & - & $(10(.91)$ & - & - & - & - \\
\hline A & $\mathrm{X}$ & 27,0 & 2.63 & 47 & *6 (.13) & $26(.55)$ & 2 & - & 11 & $* 6(55)$ \\
\hline A & XII & 28,2 & 2.90 & 55 & 3 (.05) & $43(.78)$ & - & - & 15 & $14(.93)$ \\
\hline B & XVI & 31,2 & 3.58 & 286 & 13 (.05) & $263(.92)$ & 4 & $4(1.0)$ & 19 & $17(.90)$ \\
\hline $\mathrm{C}$ & XVIII & 33,3 & $3 \cdot 30$ & 105 & $22(.21)$ & $83(.79)$ & - & - & 20 & $19(.95)$ \\
\hline $\mathrm{D}$ & XIX & 35,0 & 3.05 & 276 & $20(.07)$ & $248(.90)$ & 16 & ${ }^{*} 15(.94)$ & - & \\
\hline $\mathrm{D}$ & $\mathrm{XX}$ & 38,0 & 3.57 & 103 & $47(.46)$ & $49(.47)$ & 7 & $7(1.0)$ & - & \\
\hline
\end{tabular}

aObservation texts were examined only until to was used in $95 \%$ of obligatory noun contexts.

bPeriod represents texts pooled for presenting group results.

cNumbers in parentheses are the proportional occurrence of to in the total contexts.

dStarred frequency indicates first productivity of $t o$.

If the children had learned to in the context of complement verbs as a marker of the infinitive form, then any difference in the distribution of to would be expected to occur developmentally with complement verbs, and not with the matrix forms. The children initially used a small group of matrix verbs, primarily want and go and, less often, got and have. These earliest verbs appeared to function as modal verbs to express the child's mood of wish or intention (see Bloom, Lightbown, \& Hood, 1975; Brown, 1973), with a wide variety of different main verbs, for example:

(11a) [ə] want put in there.

(11b) I want open it.

(11c) I gonna get it. 
The modal verbs (want, go, got, and have) were the most frequent matrix forms used by each child; at the time of the first observation, they were the only matrix forms used by three of the children and accounted for $85 \%$ of the forms used by the fourth child (Eric). When the modal verbs emerged, they were used primarily without the connective to or with some variant of [ə], for example, wanna, gotta, halfta.

Nonmodal matrix forms (e.g., try and ready) appeared after the modals; when they appeared they were used proportionately more often with to than without, and they did not occur with [ə]. The use of to increased substantially with the modals only after to was used frequently with these other new matrix forms. This developmental regularity in the use of to with different kinds of matrix forms (nonmodals and then modals) is presented in Figure 1. (The frequencies in Figure 1 represent the frequency of to only, with occurrence of [ə] excluded.) In contrast, no developmental patterns were evident among the different verbs used as infinitive complements in these same sentences.

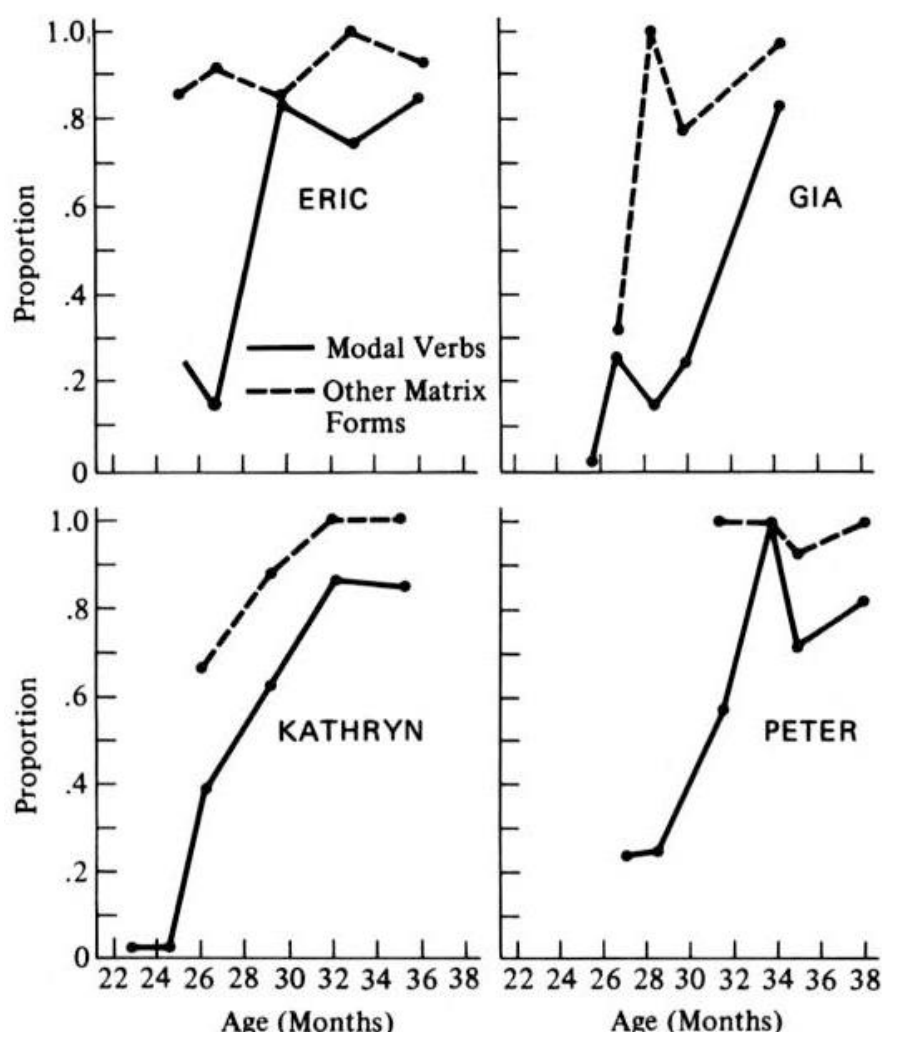

Figure 1. Increase in the use of to in modal and other matrix forms.

\section{Distribution of to with Old and New Matrix Forms}

The use of to was compared in CV contexts with new and old matrix and complement verbs. Old forms were those that had appeared in any previous observation; new forms were those that had not been observed previously (for each child considered separately). The expression of to increased developmentally, as can be seen in Figure 2, in the four developmental periods. However, to was always more frequent with new matrix forms, and [ə] was more frequent with old matrix forms. These differences were especially pronounced after Period A. This result is not entirely independent of the result presented in Figure 1, where to emerged with the nonmodal matrix forms first and with the modals later. The modals, which were most frequent, were always among the old forms. 


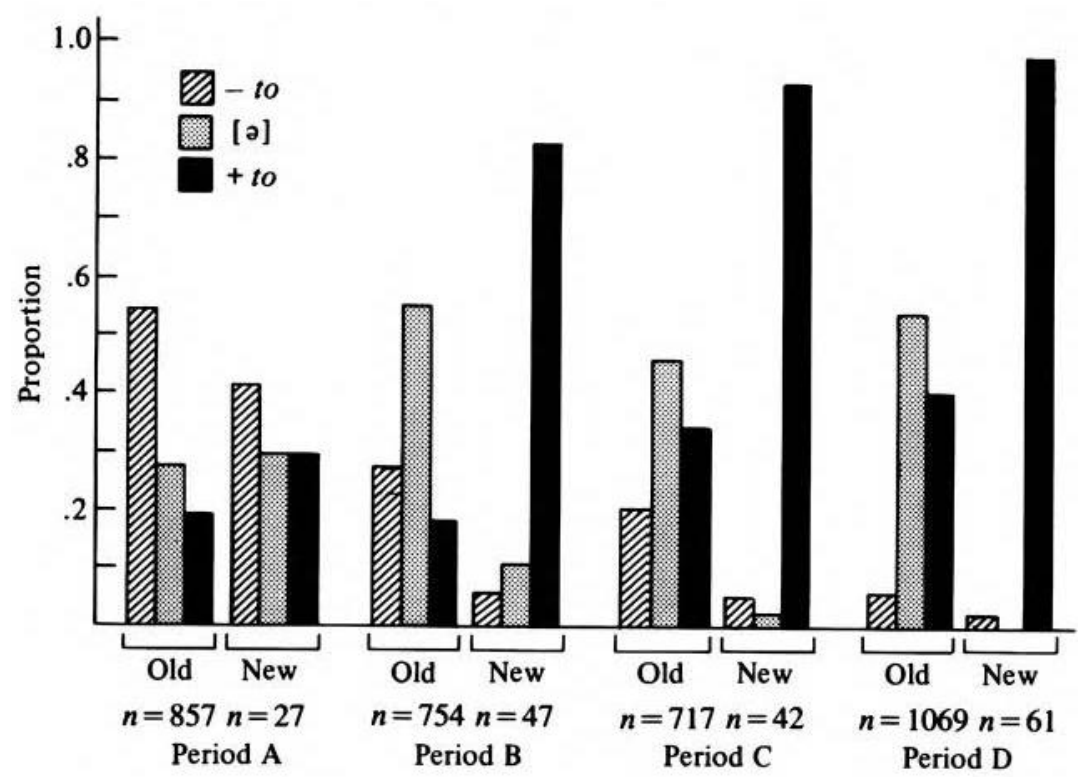

Figure 2. Comparison of old and new matrix forms in the use of to, in the four longitudinal periods

In contrast, each of the children used an average of 100 or more different complement verbs in these same sentences, and there were neither distributional regularities nor developmental differences among complement verbs in the expression of to or [ə]. Moreover, no systematic distribution of to occurred among old and new complement verbs, either developmentally or overall, as can be seen in Figure 3. Thus the matrix forms and not the complement verbs controlled the emergence of to. First, to was acquired differently with different kinds of matrix forms, and second, to was always more likely to occur with new than with old matrix forms. In contrast, no developmental regularity was observed in the use of to with the children's complement verbs.

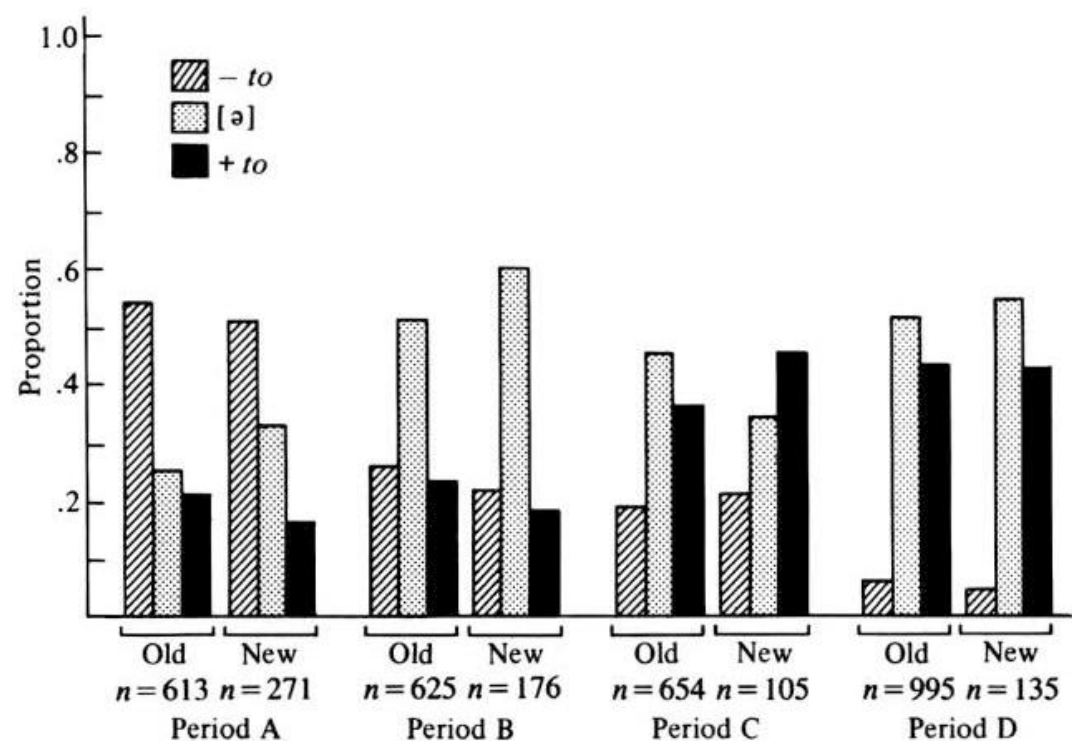

Figure 3. Comparison of old and new complement verbs in the use of to in the four longitudinal periods 


\section{Occurrence of to with an Intervening Noun Phrase}

The final analysis of the distribution of to in CV contexts concerned the context with an intervening noun phrase: V1-NP-to-V2, where the subject of the second, complement verb was not coreferential with the subject of the matrix form. There were 163 of these contexts for to (.04 of all the utterances with a CV context for to). With one exception, these $\mathrm{CV}$ contexts for to with an intervening noun phrase did not occur until after to was already expressed in more than .75 of the contexts with modals and MLU was about 3.5. The one exception was Kathryn, who in the earliest texts produced several sentences where the matrix form was the modal verb want followed by a sentence without to (see Table 1), for example:

(12a) want the man stand up

(12b) I want Mommy get it.

These contexts then decreased (Observations VI and VIII for Kathryn, Table 1). In the last observation, when they were again frequent, to was expressed, and the intervening NP was the pronoun you most often.

Except for Kathryn, then, CV contexts with an intervening, non-coreferential NP were infrequent early on. When they did eventually become productive for all the children, to was used at least $90 \%$ of the time (Table 1). Only three instances of [ə] occurred in this context-one after and two before the intervening NP; (13a) and (13b) occurred in Kathryn II and (13c) in Kathryn III:

(13a) want Kathryn [ə] put in [ə] tank

(13b) [ə] want [ə] Kathryn find [ə] lipstick

(13c) [ə] want [ə] Kathryn read/read this book.

Sentences with intervening, non-coreferential NP were highly constrained; they were different for the different children; and they were sometimes different for the same child at different times. Five kinds of structures occurred:

(14) V1-NP-to-V2, where NP was me or you, and V1 was want most often:

(a) Want me to do it?

(b) I'll help you to find the buttons

(15) V1-NP-to-V2, where NP was a nominal:

I want this doll to stay here

(16) for-NP-to phrases, where V1 was a form other than want, like, or ask:

It's hard for you to eat your thing

(17) intervening NP that functioned as object of both V1 and V2:

(a) need something to eat

(b) I want something to do

(18) how to phrases after verbs such as show and teach:

I'll show you how to work it.

The individual children tended to use one or another of these kinds of sentences. Kathryn used (14), and Eric used (17). While Gia used both (15) and (16) and Peter used both (14) and (17), one or another predominated at different times. How to phrases, (18), were the least frequent and were used by only two children (Kathryn and Peter).

\section{For-to Complement Structures}

The children produced for complementizer connectives (see 16 above) only rarely and only toward the end of the period under study here. Kathryn produced two; Eric and Peter each produced one. Only Gia produced a sizable 
number (12), and these occurred in the last observation when she was 34 months, 2 weeks. Moreover, only Peter produced the for complementizer after a verb (one instance):

(19) I wait for you to fix it.

In all the other sentences, the for complementizer occurred after nouns or adjectives: ten instances of time for, three instances of hard for, and one instance each of too early for, enough for, and ready for. It appears, then, that the use of for complementizers was lexically specific rather than the result of a generalized syntactic rule for complementation when it first began to appear in these children's speech.

\section{Semantics of to}

The overwhelming majority of the matrix forms that provided the CV contexts for to shared an element of meaning that was best characterized as indicating direction or movement toward the activity named by the complement verb. This semantic consistency, meaning "direction toward," was prefigured by the meaning of the first modals, want and go, which signaled the child's wish or intention toward performing the action named by the complement verb. Similarly, the next most frequent matrix forms were like, suppose, and the inchoative forms time, try, ready, and about, which also indicated direction toward the activity or state of affairs named by the complement verb. In all, $99 \%$ of the instances (i.e., tokens) of the matrix forms that the children used shared the meaning "direction toward." Even when the modals want, go, have, and got were not counted, $84 \%$ of the remaining tokens of other modals shared this same meaning.

The $1 \%$ of modal tokens that did not themselves express direction toward were used most often with complement verbs that expressed a locative action with direction toward, for example:

(20a) forgot to bring.

(20b) too far to walk.

(20c) long way to go.

(2od) forgot to take.

(20e) used to go.

These matrix forms appeared to express negation of the meaning "direction toward." There were only isolated instances where the interpretation "direction toward" was not tenable, for example:

(21a) forgot to dry.

(21b) hard to read.

Table 2. Matrix Forms That Provided Complement Verb Contexts for $t o^{\mathrm{a}}$

\begin{tabular}{lllll}
\hline $\begin{array}{l}\text { Intention } \\
\text { (modals) }\end{array}$ & Inchoative & Invitative & Instructive & Negative \\
\hline want & try & like & show how & forgot \\
go & time & supposed & know how & hard \\
have & ready & get & know what & used \\
got & about & fun $^{\mathrm{b}}$ & know where & (too) far \\
& need & safe $^{\mathrm{b}}$ & tell & long way \\
& start & nice & ask & not nice \\
& be able ${ }^{\mathrm{b}}$ & easier & teach how & wait \\
& & & & afraid \\
& & & & too noisy \\
& & & too early \\
& & & too ugly \\
& & & too bigb \\
\hline
\end{tabular}

aListed in order of frequency for all children combined.

bSingle instance only. 
All the matrix forms are listed in Table 2, in order of frequency and categorized as expressions of intention, inchoative, invitative, instructive, and negative meaning. This categorization is only suggestive. Obviously, each of the child forms in Table 2 is semantically complex, but the taxonomy (intentional, inchoative, invitative, and instructive meanings) is intuitively likely, based upon our adult understanding of the forms. The purpose of the taxonomy is to highlight the interpretation of direction toward, and to demonstrate that the children learned the complementizer connective to in the context of that meaning. This interpretation, moreover, is consistent with the historical meaning of the connective to derived from the meaning of the preposition to with nouns (Jespersen, 1964).

\section{Comparison of to in Verb and Noun Contexts}

One question that remained was how the acquisition of to in CV contexts (e.g., "going to sleep"), related to the acquisition of to in noun contexts (e.g., "going to school"). As seen in Table 1, to was learned in noun contexts either at the same time (by three of the children) or later (by Kathryn) than in CV contexts, and use of to increased developmentally in both contexts. Contrary to our intuitive expectations, there were many more CV contexts for to than there were $\mathrm{N}$ contexts. However, even though the children had more opportunities to use to in CV contexts than in $\mathrm{N}$ contexts, given an $\mathrm{N}$ context, to was more likely to occur (overall average .66) than when given a CV context (overall average .28). Further, there was some tendency that given a noun context for to, to was more likely to occur if that noun was an animate noun than if it was an inanimate noun. Inasmuch as the preposition to in noun contexts in the children's speech always meant direction toward," the fact that they learned to in verb contexts at essentially the same time that they learned to in noun contexts added support to the conclusion that they learned to in verb contexts also with that meaning.

\section{DISCUSSION}

The spontaneous speech data from these four children support the following conclusions regarding to in the development of the verb system in their language: First, the children in this study did not learn to as a meaningless syntactic marker. The interpretation of to as "direction toward" was based upon the meaning of the matrix forms with which to was learned. The children's use of to was consistent with the historical meaning "direction toward" or "goal" (Jespersen, 1964) and, indeed, the appearance of to in their speech with both nouns and verbs was closely associated in time.

Second, these 2-year-old children learned to as a complementizer connective in the context of a small group of forms that take a verb phrase complement; the basic structure that they learned was verb + to. A limited set of matrix forms occurred that took the connective to, and a large and varied set of verbs occurred freely as complements. The children did not learn to in the context of the complement verbs to mark the infinitive.

The thrust of this conclusion is not diminished by the appearance of an intervening and non-coreferential NP to separate the matrix form and to in the surface structure. Utterances with intervening NP were relatively infrequent; the matrix forms were the same forms as in contexts without intervening NP, and the to was expressed with intervening NP later and only after the children had learned to well enough to use it in more than $75 \%$ of the CV contexts. Moreover, the structures with intervening NP were highly constrained: Certain structures were used by only one or two of the children and only with limited lexical-syntactic surface structure realization. For example, in the later data, when Kathryn used to with an intervening NP, she used want overwhelmingly with you as the intervening NP. The to was otherwise part of a fuller connective, for example, how to or for to, with specific matrix forms (e.g., show-how to, too hard for-to). These children were just beginning to acquire the complexities of surface-structure syntax with to. Having already established the basic structure of to with matrix forms in CV contexts, the children began to learn more complex complementizer structures that were specific to particular matrix forms.

In sum, the children learned to complements in the context of a small number of verbs and modal forms. Other aspects of these children's acquisition of linguistic structure have been verb specific as well: for example, the 
constituent structure of early sentences (Bloom, Miller, and Hood, 1975), the acquisition of inflections (Bloom, Lifter, \& Hafitz, 1980), and the acquisition of wh-questions (Bloom, Merkin, \& Wootten 1982). 4

We have identified three hypotheses that converge to explain the acquisition of to in the present study. They are complementary rather than mutually exclusive. First, a semantic hypothesis would suggest that syntactic learning is somehow directed to or at least facilitated by semantic categorization (e.g., Bloom, 1970; Slobin, 1973), as in this instance where to was acquired with the meaning direction toward. The second hypothesis, a formal one, would predict that to is acquired as children come to recognize the distributional regularity of to in adult speech (e.g., as Braine, 1976; and Maratsos \& Chalkley, 1980, have argued for other linguistic forms in child data). Evidence for this position would be the strong association of to with matrix forms and the fact that when sentences with an intervening non-coreferential NP began to appear, the structures were highly constrained in form and different for each of the children. The third explanation is a processing hypothesis: that children begin to use to in appropriate contexts as a function of their increasing ability to process longer utterances, unstressed elements, and complement structures. Thus the children learned to use to more easily with new forms than with the old forms that were already well established without to.

With respect to linguistic theory, the results of this study are more consistent with the lexicalist theory of universal grammar (Bresnan, 1978) than the transformational account (Koster \& May, 1982). The child data support Bresnan's view that verb + infinitive and modal + infinitive are basic structures. However, in the present study the evidence indicated that the children learned to as a complementizer connective with the higher verb and other matrix forms, and the basic structure that they learned originally was verb + to. The children did not appear to learn the same underlying sentential structure for for-to and infinitive complements (Koster \& May, 1982). The transformational account of simpler structures being derived from more complex underlying sentential structures finds no support. This conclusion is consistent with a similar conclusion regarding phrasal and sentential coordination reported by Bloom, Lahey, Hood, Lifter, and Fiess (1980), Lust and Mervis (1980), and Tager-Flusberg, de Villiers, and Hakuta (1982).

The results of this study support the conclusion that we have drawn elsewhere: The verb system is a determining factor in the acquisition of linguistic structure (see in particular Bloom, 1981; Bloom, Lightbown, \& Hood, 1975; Gentner, 1978; and Lahey \& Feier, 1982, regarding language dissolution). The subcategorization of verbs exerts a major influence on the acquisition of increasingly complex structures in children's sentences, and the development of the verb lexicon and the grammar are mutually dependent.

\footnotetext{
4 The main result of this study, that the children learned to in the basic structure verb + to, is consistent with the results of a subsequent study of the acquisition of other complementation structures by the same four children (Bloom, Rispoli, Gartner, \& Hafitz, 1989). In the same period, from two to three years of age, the children learned a small number of complement-taking verbs in addition to the verbs with to: The most frequent were the perception verbs see and look, mental verbs know and think, and communication verbs say and tell. The children acquired the wh-connectives complementizer connectives that were specific to individual verbs the. They did not use them in all possible contexts, not even with verbs already established in their lexicons that could be expected to take $w h$-connectives. Similarly, to was specific to the matrix forms described here. In both studies, the basic structure that the children learned was verb + connective. That is, the first verb in a sentence governed whether a connective occurred and, if a connective occurred, which one.
} 


\section{References}

Bloom, L. (1970). Language development: Form and function in emerging grammars. Cambridge, MA: MIT Press.

Bloom, L. (1981). The importance of language for language development: Linguistic determinism in the 1980s. In H. Winitz (Ed.), Native language and foreign language acquisition (vol. 379, pp. 160-71). New York: New York Academy of Sciences.

Bloom, L. (1991). Language development from two to three. New York: Cambridge University Press.

Bloom, L. (1992). Racism in developmental research. President's Message, Division 7 Newsletter. Washington, DC: American Psychological Association, Fall-Winter.

Bloom, L., Lahey, M., Hood, L., Lifter, K., \& Fiess, K. (1980). Complex sentences: Acquisition of syntactic connectives and the semantic relations they encode. Journal of Child Language, 7, 235-61.

Bloom, L., \& Lahey, M. (1978). Language development and language disorders. New York: Wiley.

Bloom, L., Lifter, K., \& Hafitz, J. (1980). Semantics of verbs and the development of verb inflection in child language. Language, 56, 386-412.

Bloom, L., Lightbown, P., \& Hood, L. (1975). Structure and variation in child language. Monographs of the Society for Research in Child Development, 40 (serial no. 160).

Bloom, L., Merkin, S., \& Wootten, J. (1982). Wh-questions: Linguistic factors that contribute to the sequence of acquisition. Child Development, 53, 1084-92.

Bloom, L., Miller, P., \& Hood, L. (1975). Variation and reduction as aspects of competence in language development. In A. Pick (Ed.), Minnesota symposia on child psychology (vol. 9, pp. 3-55). Minneapolis: University of Minnesota Press.

Bloom, L., Rispoli, M., Gartner, B., \& Hafitz, J. (1989). Acquisition of complementation. Journal of Child Language, 16, 101-20.

Braine, M. (1976). Children's first word combinations. Monographs of the Society for Research in Child Development, 41 (serial no. 164).

Bresnan, J. (1970). On complementizers: Towards a syntactic theory of complement types. Foundations of Language, 6, 297-321.

Bresnan, J. (1978). A realistic transformational grammar. In M. Halle, J. Bresnan, \& G. Miller (Eds.), Linguistic theory and psychological reality (pp. 1-59). Cambridge, MA: MIT Press.

Brown, R. (1973). A first language, the early stages. Cambridge, MA: Harvard University Press.

Gentner, D. (1978). On relational meaning: The acquisition of verb meaning. Child Development, 49, 988-98.

Jespersen, O. (1964). Essentials of English grammar. Tuscaloosa: University of Alabama Press.

Koster, J., \& May, R. (1982). On the constituency of infinitives. Language, 58, 116-43.

Lahey, M., \& Feier, C. (1982). The semantics of verbs in language development and language dissolution. Journal of Speech and Hearing Research, 25, 81-95.

Limber, J. (1973). The genesis of complex sentences. In T. Moore (Ed.), Cognitive development and the acquisition of language (pp. 169-85). New York: Academic Press.

Lust, B., \& Mervis, C. (1980). Development of coordination in the natural speech of young children. Journal of Child Language, 7, 279-304.

Maratsos, M., \& Chalkley, M. (1980). The internal language of children's syntax: The ontogenesis and representation of syntactic categories. In K. Nelson (Ed.), Children's language (vol. 2, pp. 127-214). New York: Gardner Press. 
Quirk, R., Greenbaum, S., Leech, G., \& Svartvik, J. (1972). A grammar of contemporary English. London: Longman Group.

Rosenbaum, P. (1967). The grammar of English predicate complement constructions. Cambridge, MA: MIT Press.

Slobin, D. (1973). Cognitive prerequisites for the development of grammar. In C. Ferguson \& D. Slobin (Eds.), Studies of child language development (pp. 175-208). New York: Holt, Rinehart \& Winston.

Tager-Flusberg, H., de Villiers, J., \& Hakuta, K. (1982). The development of sentence coordination. In S. Kuczaj (Ed.), Language development: Problems, theories, and controversies (vol. 1, pp. 201-43). Hillsdale, NJ: Erlbaum. 